\title{
13. Holonic Manufacturing Control: Rationales, Developments and Open Issues
}

\author{
Duncan C. McFarlane ${ }^{1}$ and Stefan Bussmann ${ }^{2}$ \\ ${ }^{1}$ Institute for Manufacturing \\ University of Cambridge \\ United Kingdom \\ Email: dcm@eng.cam.ac.uk \\ ${ }^{2}$ DaimlerChrysler AG \\ Research and Technology \\ Berlin, Germany \\ Email:Stefan.Bussmann@daimlerchrysler.com
}

\begin{abstract}
Holonic manufacturing systems support a more plug-and-play approach to configuring and operating manufacturing processes, and thereby address increasing efforts to meet the needs for market responsiveness and mass customised products. This chapter is primarily concerned with the control approaches associated with holonic manufacturing systems. It addresses three key issues. Firstly, a clear business rationale for a holonic approach to manufacturing control is outlined. Secondly, a number of the key developments in holonic control systems are summarised. Finally a number of outstanding issues for the design and implementation of holonic control systems are highlighted.
\end{abstract}

\subsection{Introduction}

The concept of holonic manufacturing was introduced by Suda in the early 1990s $[13.58,13.59]$ to address emerging challenges for manufacturing in the 21 st century. It is intended to enable a "plug and play" approach to designing and operating a manufacturing system. In the last ten years, an increasing amount of research has been devoted to holonic manufacturing over a diverse range of both theoretical issues and industrial applications. This chapter draws on and extends previous research by the authors examining the rationale for holonic control and its developments [13.13], [13.47]. It describes a vision for holonic manufacturing and assesses how that vision matches the current needs of manufacturing businesses. It then briefly reviews current research in holonic control systems development and outlines a number of open issues that must be addressed before holonic control systems can be deployed industrially.

\subsubsection{Background to Holonic Systems}

The holonic concept was proposed by the philosopher Arthur Koestler in order to explain the evolution of biological and social systems [13.37]. He made two key observations: 
1. These systems evolve and grow to satisfy increasingly complex and changing needs by creating stable "intermediate" forms which are self-reliant and more capable than the initial systems.

2. In living and organisational systems it is generally difficult to distinguish between 'wholes' and 'parts': almost every distinguishable element is simultaneously a whole (an essentially autonomous body) and a part (an integrated section of a larger, more capable body).

These observations led Koestler to propose the word "holon", which is a combination of the Greek word holos meaning whole and the Greek suffix on meaning particle or part as in proton or neutron. Suda's observation [13.58,13.59] was that such properties would be highly desirable in a manufacturing operation which is subject to increasingly stringent demands and faster changes. He therefore proposed a buildingblock or "holon"-based model for designing and operating elements comprising manufacturing processes similar in concept to the one defined in [13.12] which is outlined in Fig. 13.1.

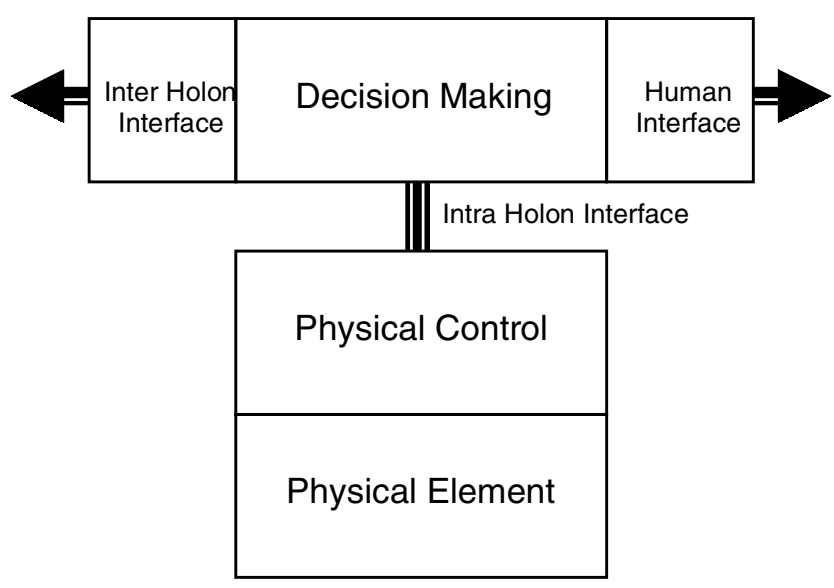

Fig. 13.1. General architecture of a holon

Some key properties of a (holonic) manufacturing system developed from this model are:

- Autonomy - the capability of a manufacturing unit to create and control the execution of its own plans and/or strategies (and to maintain its own functions).

- Cooperation - the process whereby a set of manufacturing units develop mutually acceptable plans and execute them.

- Selforganisation - the ability of manufacturing units to collect and arrange themselves in order to achieve a production goal.

- Reconfigurability - the ability of a function of a manufacturing unit to be simply altered in a timely and cost effective manner. 


\subsubsection{Holonic Manufacturing Systems}

We now provide some simple descriptions, definitions and examples of holons and holonic manufacturing systems. We define a manufacturing holon as "an autonomous and cooperative building block of a manufacturing system for transforming, transporting, storing physical and information objects" [13.17]. It consists of a control part and an optional physical processing part (see Fig. 13.1.) Hence, for example, a suitable combination of a machine tool, an NC controller and an operator interacting via a suitable interface could form a holon which transforms physical objects in a manufacturing environment. Other examples of manufacturing holons could be products and their associated production plans, customer orders and information-processing functions. A holon can itself also consist of other holons which provide the necessary processing, information, and human interfaces to the outside world. A "system of holons which can cooperate to achieve a goal or objective"' is then called a holarchy [13.17]. Holarchies can be created and dissolved dynamically depending on the current needs of the manufacturing process.

Hence, the intention is that a combination of different holons will be responsible for the entire production operation, including not only the production planning and control functions, but also the physical transformation of raw materials into products, the management of the equipment performing the production tasks, and the necessary reporting functions. In this case the set of holons is referred to as a holonic manufacturing system. A holonic-systems view of the manufacturing operation is one of creating a working manufacturing environment from the bottom up. By providing the facilities within holons to both (a) support all production and control functions required to complete production tasks and (b) manage the underlying equipment and systems, a complete production systems is built up like a jigsaw puzzle!

Since 1990 there has been a significant amount of reported research and a wide range of publications produced that refer to control systems in a holonic context:

- conceptual descriptions - providing a high-level overview of the way in which holonic control systems might be structured and might function $[13.5,13.6,13.17$, $13.47,13.49,13.57,13.58,13.62,13.65,13.67]$.

- specific architectural designs and specifications - providing detailed descriptions of the different functions of a holon and its interconnection with other holons and the way the holons operate. A range of architectures have been proposed in the literature - some more feasible than others $[13.10,13.12,13.17,13.28,13.29,13.30$, $13.38,13.45,13.46,13.50,13.56,13.63,13.66,13.67,13.68]$.

- distributed algorithm design - a number of authors have also developed algorithms, protocols and interaction mechanisms which underpin holonic operating methodologies $[13.4,13.7,13.8,13.9,13.19,13.21,13.20,13.28,13.33,13.34$, $13.39,13.43,13.44,13.48,13.53,13.63,13.70,13.71,13.72]$.

- simulated or prototype implementations - are less prevalent in the literature and have generally been proof of concept level implementations as opposed to industrial implementations $[13.1,13.4,13.15,13.14,13.26,13.28,13.29,13.31,13.32$, $13.36,13.43,13.60,13.61,13.62,13.65,13.66]$. 
Despite the level of intensity applied to this work, there are a significant number of gaps which must be filled before holonic control can become an industrial reality. This is addressed in the latter part of this chapter.

\subsubsection{Manufacturing Control in a Holonic Context}

Holonic manufacturing represents an alternative approach to designing manufacturing systems to Computer Integrated Manufacturing (CIM), as an integrating methodology for computer control in manufacturing. The difference may be summarised as a contrast between a so called top down approach and a so called bottom up approach. For the last 15-20 years, CIM has been a blueprint for the design and specification of hierarchical, centralised computer-based operations, while holonic manufacturing represents a possible blueprint for distributed computer-based manufacturing operations which support local decision making. (See [13.40] for a detailed comparison between CIM and holonic manufacturing.) We conclude this section by summarising some of the primary differences between holonic control solutions and their conventional counterparts. Fig. 13.2 lists the main differences between conventional CIMbased and holonic approaches to production control. A preliminary version of this table was given in [13.47]. Fundamentally, the holonic characteristics are intended to provide for a "plug and play" control environment which is as simple to add to, remove from, or reconfigure as are today's computer networks.

\begin{tabular}{|c|c|c|}
\hline & Conventional control solution & Holonic control solution \\
\hline 1 & $\begin{array}{l}\text { The intended product is closely- } \\
\text { considered in the design of the plant } \\
\text { and its control system }\end{array}$ & $\begin{array}{l}\text { The holonic resources and their controls } \\
\text { are designed independently of any particu- } \\
\text { lar products }\end{array}$ \\
\hline 2 & $\begin{array}{l}\text { Fixed layered, hierarchical archi- } \\
\text { tecture representing the different } \\
\text { production control functions }\end{array}$ & $\begin{array}{l}\text { Dynamically changing hierarchy of con- } \\
\text { trol functions }\end{array}$ \\
\hline 3 & $\begin{array}{l}\text { Command/response mechanism } \\
\text { provides the basis for the connection } \\
\text { between different production control } \\
\text { functions }\end{array}$ & $\begin{array}{l}\text { Interactive interchange / simultaneous } \\
\text { solution is possible between different pro- } \\
\text { duction control functionss }\end{array}$ \\
\hline 4 & $\begin{array}{l}\text { Predetermined solution } \\
\text { for individual production } \\
\text { functions }\end{array}$ & $\begin{array}{l}\text { Control strategy determined by the na- } \\
\text { ture of the operation required and the dif- } \\
\text { ferent holons involved }\end{array}$ \\
\hline 5 & $\begin{array}{l}\text { Typically a centralised solver for } \\
\text { each individual production control } \\
\text { function }\end{array}$ & $\begin{array}{l}\text { Typically a distributed solver, with co- } \\
\text { operative interactions between nodes, and } \\
\text { simultaneously addressing more than one } \\
\text { control function }\end{array}$ \\
\hline 6 & $\begin{array}{l}\text { Control solution time constrained } \\
\text { by processing power }\end{array}$ & $\begin{array}{l}\text { Control solution time constrained by } \\
\text { communications speed }\end{array}$ \\
\hline
\end{tabular}

Fig. 13.2. Characteristics of Conventional and Holonic Control

Like CIM, holonic manufacturing approaches have already exploited and will continue to exploit many existing technologies and methods. For example, the manufacturing control approaches appearing in the holonic literature have many characteristics in common with existing developments in heterarchical manufacturing control 
(see, for example, [13.22, 13.23, 13.24, 13.25, 13.41, 13.42]), intelligent scheduling (see $[13.52,13.73]$ and the references therein) and in multi agent systems $[13.2,13.12$, 13.35].

\subsubsection{A Simple Example of Holonic Manufacturing Operations}

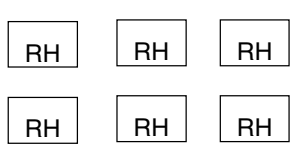

(a)

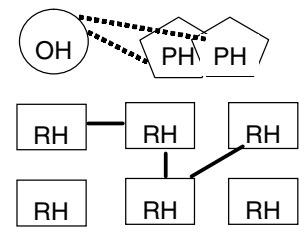

(c)

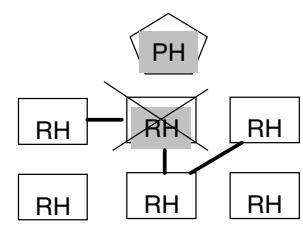

(e)

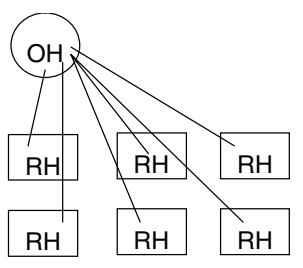

(b)

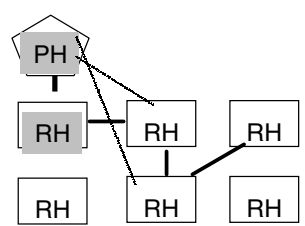

(d)

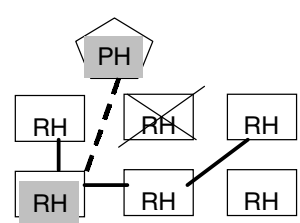

(f)

Fig. 13.3. Selforganisation of order processing.

In order to better illustrate the characteristics of holonic control systems described above, we now provide a simple example. This illustration is an extension of an example that appeared in $[13.13,13.47]$ and is outlined in Fig. 13.3. Initially (referring to Fig. 13.3a), a factory based on the holonic manufacturing principles consists only of a pool of unassigned resource holons (RHs). As discussed in Figure 13.2, there is no a-priori relationship between the different resources and no pre-determined control code has been written in anticipation of future orders. Hence, upon arrival of an order, an order holon $(\mathrm{OH})$ is created which - empowered with customer order requirements and product specifications - begins to negotiate with resource holons regarding the provision of certain manufacturing operations (Fig 13.3b). During the negotiation process, the order holon demands specific properties required from the operation, such as high quality or fast delivery, while the resource holons try to optimise their utilization - for example, to ensure high overall throughput for the factory. At the end 
of the negotiation, the resource holons form an agreed "production-line" and the order holon initiates the creation of product or workpiece holons (PHs) as in Figure 13.3c.

The product holons enter the newly formed "production line" (e.g., from rawmaterial stock) and immediately bargain for appropriate resources as specified from the order negotiation in order to get processed. Each product holon does so individually and focuses on the next operation(s). Once these operations have been performed at a resource, the product re-initiates the bargaining with the holons representing the remaining (next) operations (Fig 13.3d). The overall organisation of the resource holarchy - initially or subsequently negotiated between order and resource holons ensures that the product load is efficiently distributed over the available resources in order to achieve the global goals of this holarchy.

In the case of a disturbance (Fig 13.3e), the affected resource holon removes itself from the resource pool and goes to a repair booth. The remaining resource holons reorganise themselves in order to take account of the capacity loss (Fig 13.3f). From the point of view of the product holons, the processing continues as business as usual, only with fewer resource holons to negotiate with. After repair, the resource holon rejoins the resource holon pool again.

At the end of the order processing, the order holon is removed and the resource holarchy dissolves into the resource holons, which then try to participate in new order holarchies.

\subsection{Manufacturing Requirements Analysis}

Manufacturing operations are not an end in themselves, but serve as a means to achieve the business goals of a company. It is therefore essential for an evaluation or comparison of manufacturing concepts to identify the requirements on the manufacturing process against which the concepts should be evaluated. These requirements are derived from the business goals and the given or expected market conditions. Business goals and market conditions, however, may change over time and thus the set of manufacturing requirements may change. A manufacturing approach that has been sufficient until now, may result in a poor performance in the future. Consequently, manufacturing concepts should be evaluated not only against the existing requirements, but also against future (possibly unknown) requirements. This section therefore looks at the current business trends and shows how these will change the manufacturing environment. The new manufacturing requirements are then used to derive requirements on the control of future manufacturing systems. This process is outlined in Fig. 13.4. 


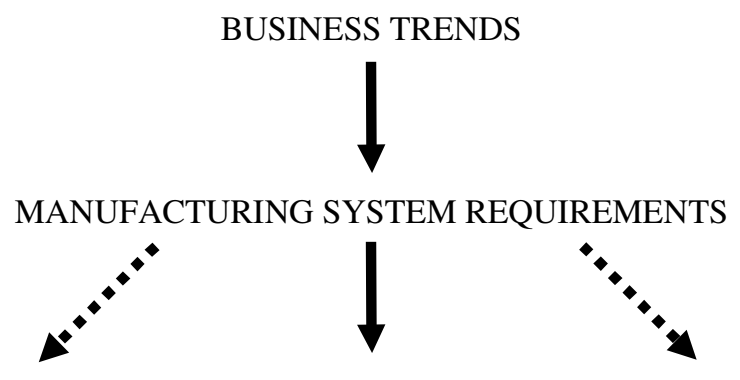

CONTROL SYSTEM PROPERTIES

Fig. 13.4. Requirements Break Down Process.

We note that the initial development of these results was made specifically with the automobile industry in mind [13.13]. The results have since been validated however against the requirements of Fast Moving Consumer Goods (FMCG) companies and several other types of manufacturers.

\subsubsection{Business Trends}

It is difficult to estimate what the business requirements of the 21 st century will be. The current requirements of producing goods of a specific quality at low cos will certainly remain in place. But the current market trends suggest that additional requirements will arise which will determine the competitiveness of a company and thus its survival in this century.

Recently, manufacturing industry has been facing a continuous change from a supplier's to a customer's market. The growing surplus of industrial capacity provides the customer with a greater choice, and increases the competition between suppliers. Aware of this power, the customer becomes more demanding and less loyal to a particular product brand. He/she demands constant product innovation, low-cost customisation and better service, and chooses the product which meets his requirements best. In combination with globalisation, these trends will increase in the future.

The consequences for the manufacturing industry are manifold. Companies must shorten product life cycles, reduce time-to-market, increase product variety and instantly satisfy demand, while maintaining quality and reducing investment costs. These consequences imply:

- $\quad$ more complex products (because of more features and more variants),

- faster changing products (because of reduced product life-cycles),

- faster introduction of products (because of reduced time-to-market),

- a volatile output (in total volume and variant mix), and

- $\quad$ reduced investment (per product).

The effects can be summarised as increasing complexity and continual change with decreasing costs. 


\subsubsection{Manufacturing System Requirements}

Most existing requirements placed on a manufacturing operation will still apply in the future. These include guaranteed performance, high reliability of equipment, quality assurance, cost minimisation etc. Given the trends described in the previous section, though, additional requirements will become relevant, if not predominant.

- Increasing complexity: A major requirement will be to minimise the complexity of the manufacturing process (despite the likely increases in the variety of products and product ranges). This can be achieved basically by reducing the number of manufacturing system components and by standardising the structure of these components and their interaction. Nevertheless, there is a limit to reduction and standardisation, as a complex product requires a certain set of complex operations. The remaining process complexity must be mastered. This can be achieved on the one hand by creating an intuitive, self-explaining structure of the manufacturing (and control) system, and on the other hand by ensuring a well-defined behaviour upon certain actions and events. Ideally, the control layer of a manufacturing system should be completely transparent to the end-user, and any actions or events should exhibit well-known effects on the overall system performance. In particular, the control layer should not introduce additional complexity and the overall behaviour of a manufacturing system should be well defined under all circumstances.

- Constant product changes: Constant product changes require the reuse of existing manufacturing equipment. Buying new equipment either is too costly or takes too much time. Reuse of equipment implies the reuse of the units and the reorganisation of the manufacturing process. Reuse of manufacturing units can be achieved either through flexibility of function or through reconfigurability. A unit is immediately reusable if the new operations required are part of the range and mix of operations of this unit. High functional flexibility thus increases the chances of equipment reuse. Units equipped (up front) with a large range of operations, however, can be very costly. In contrast, the costs of a unit are often reduced considerably if the reuse is provided through manual reconfigurability. For monthly product changes, this is acceptable. Weekly or daily product changes, though, are likely to require instant unit flexibility. An analogous requirement applies to process re-organisation. The manufacturing process must be either flexible or reconfigurable in order to deal with the product changes.

- Volatile Output: The volatility of the demand forces the vendors to adapt their output to the market. A product sells only when the market demands it. If a company does not supply the right product at the right time, another company makes the deal. As a consequence, the manufacturing system must be able to vary its production output. This implies scalability of the manufacturing system if the total volume changes, and inter-product flexibility if the product mix changes. Scalability can be achieved either by extending the working time or by adding more resources

- Reduced Investment and Robustness: The task of managing change becomes even more difficult if it has to be achieved at decreasing costs. A company might even decide not to provide full flexibility or reconfigurability if the costs are prohibitive. The real challenge is to manage change at low costs. A low investment approach to change management, however, creates a second difficulty, namely that of disturbances. A behaviour which is achieved under scarce resources is vulnerable to (internal and external) disturbances. Future manufacturing operations will therefore 
require increasing robustness. Robustness can be achieved either structurally or dynamically. Buffers in terms of material or time slack provide structural robustness. System flexibility allows to adapt the process to failures, for instance by using spare resources or re-routing jobs.

\subsubsection{Control System Properties}

The requirements on the manufacturing system have also implications for the control of such a system. Many requirements can only be achieved if the control system meets equivalent requirements. Requirements like unit flexibility or reconfigurability are mainly hardware issues, but system responsiveness is certainly impossible without some kind of intelligent control. This subsection therefore looks at the consequences of the new manufacturing requirements for the control, regardless of the actual design and implementation of the control system.

I. The architecture of the control should be decentralised and physically-based.

For even small manufacturing systems, a centralised approach to control is practically impossible. There must be at least some kind of decentralisation. Decentralisation, however, can take many forms. For instance, a system can be functionally or geographically distributed. But in order to allow for maximum flexibility, the decentralisation should be product- and resource-based. In a resource-based architecture, every resource contains all control capabilities necessary to process jobs. In particular, a set of resources is able to allocate jobs to resources without a centralised support. The advantage of the resource-oriented approach is that the system can be changed and scaled up fairly easily. Furthermore, the control corresponds in its structure to the manufacturing system and thus reduces the complexity added by the control system to a minimum. The control activities might even become transparent to the end-user. A similar argument applies to equipping orders and work pieces with the necessary control capabilities to get produced.

II. Control interactions should be abstract, generalised and flexible.

A resource-based control system is certainly easier to change and scale up than a centralised or functionally decentralised system. Maximum changeability, however, is only achieved if dependencies between resources are reduced to a minimum. If one resource is changed, but other resources that rely heavily on exactly this resource and its specific behaviour, then a change of single resource entails a lot of changes at other resources. Consequently, in order to achieve maximum changeability, interaction between resources should be decoupled by ensuring abstract, generalised and flexible interactions.

III. The control should be both reactive and proactive.

In order to respond to short-term changes and disturbances, the control must be reactive. This includes the ability to recognise critical situations, make decisions about the reaction, and perform corresponding actions. In contrast to traditional planning and control approaches, the product- and resource-based architecture also distributes the planning capabilities since they depend strongly on the characteristics of the resources and the product. A resource, for instance, must also participate in the alloca- 
tion of jobs or the sequencing of operations. As a result, the control must be reactive and proactive at the same time.

\section{$I V$. The control should be selforganising.}

The need to adapt the manufacturing process in the face of changes or disturbances will affect not only the resources, but also the organisation of the manufacturing process as a whole. Obviously, in a highly responsive manufacturing system, the organisation must be responsive too and this responsiveness should emerge from any (re-)configuration of the resources and rearrangement of the process.

\subsubsection{Connecting Business Drivers and Control System Needs}

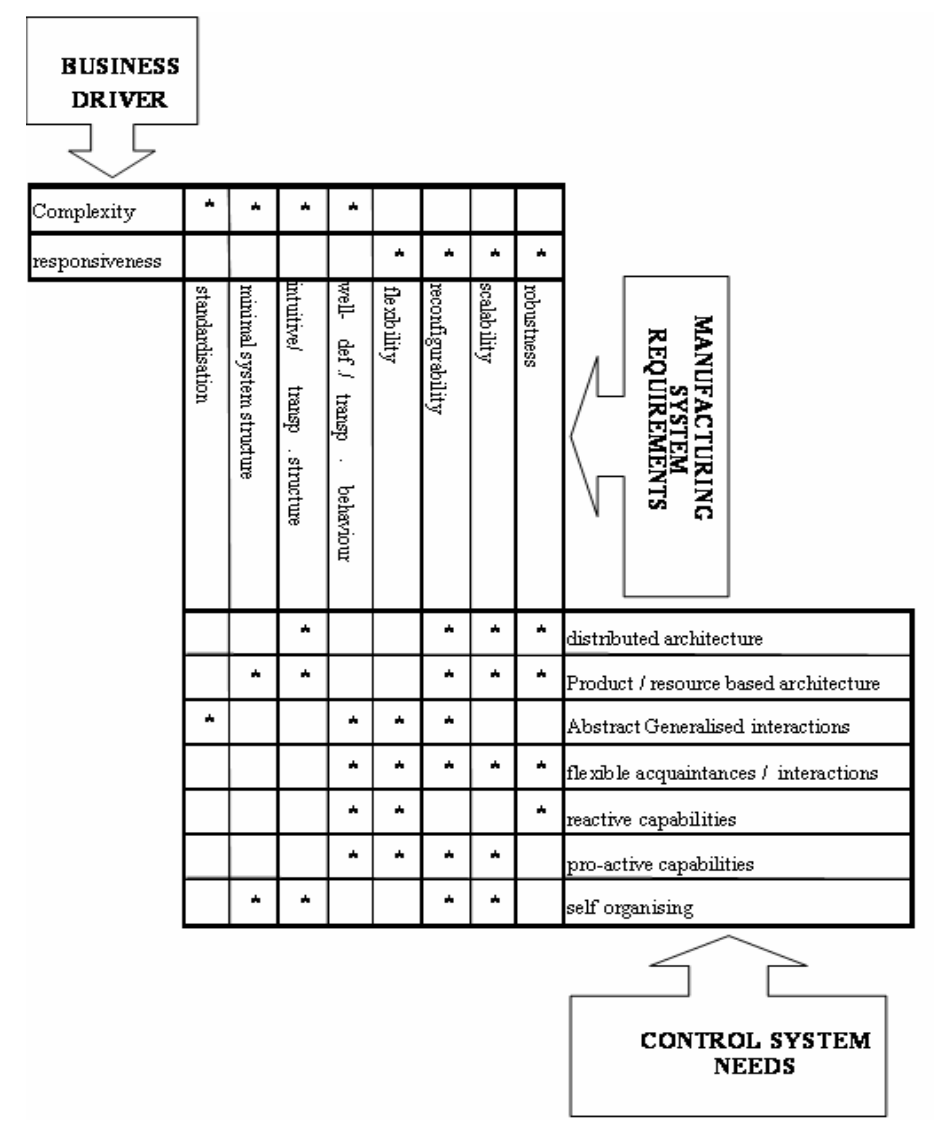

Fig. 13.5. Linking Business Drivers and Control System Needs 
The table in Figure 13.5 uses a decomposition approach to connect business drivers to control system needs, by examining the impact of the business drivers on manufacturing system requirements as an intermediary. Where a connection is important between the different levels it is marked with an asterisk.

We note that this requirements deployment is completely focused on establishing control system needs only and is hence somewhat limited as a result. A full requirements deployment would also consider - for example - factors such as human needs in terms of skills, information management, adaptability etc, or equipment requirements such as flexibility of functions, routings, fixtures, reliability of machines, processes etc. We emphasise here that holonic manufacturing is more than simply a control system and we will return to this issue in Section 13.4 in discussing conditions under which a holonic control system implementation is likely to be successful.

\subsubsection{Aligning the Holonic Control Approach with Control System Needs}

The short description of the holonic vision of manufacturing in Section 13.1.4 indicates that a holonic approach can address many of the requirements (I-IV) identified in Section 13.2.3. The requirements are met because of the basic concepts that underpin the holonic approach:

- Holonic structure - The holonic approach inherently proposes a distributed, product- and resource-based architecture for the manufacturing operations. (Requirement I)

- Autonomy - Each holon has local recognition, decision making, planning, and action taking capabilities, enabling it to behave reactively and pro-actively in a dynamic environment. (Requirements I,III)

- Cooperation - Coordination, negotiation, bargaining, and other cooperation techniques allow holons to flexibly interact with other holons in an abstract form. Because of the dynamic nature of the holarchies, each holon must employ generalised interaction patterns and manage dynamic acquaintances. (Requirement II)

- Selforganisation - Holonic manufacturing systems immediately re-negotiate the organisation of the manufacturing operations whenever the environmental conditions change. (Requirement IV)

- Reconfigurability - Because of the modular approach, holons can be reconfigured locally once the inherent flexibility of the holons has reached its limit. (Requirements II,IV)

To summarise, when fully developed, holonic manufacturing control has the potential to address many of the outstanding problems facing today's industrial control systems. The extent to which holonic control systems have been developed to date is addressed next. 


\subsection{Holonic Control Systems Development}

Architectures for the design of holonic elements and their interconnection and algorithms which define their (inter)operation represent the two key classes of developments in holonic control research to date. The principal focus of this section is to provide a brief review the development of algorithms which support holonic control systems. The reasons for this focus is that:

1. The existence of effective control algorithms is an indicator of the degree of maturity of holonic control research - without them it is not possible to assess the likely performance of a production operation running with holonic systems in place. In contrast, it is expected that numerous architectures for designing and implementing holonic control systems will continue to be proposed (as discussed in Section 13.1) and will also vary as information technology advances.

2. Algorithms supporting holonic control developed thus far can be directly contrasted with those found in conventional production control environments. This enables us to compare and contrast different holonic control developments using a common (conventional) view of production control.

3. Holonic systems architecture developments have been examined elsewhere in this book.

However, to begin, we establish some common ground, so as to be able to uniformly describe the different systems architectures used in the algorithms that follow.

\subsubsection{Holonic Control Architectures}

In order to simplify the discussions that follow, we will assume a common description of a manufacturing process operating on holonic principles. The control system is assumed to comprise software elements aligned with the different physical entities in the manufacturing environment, namely, resources, products, customer orders and coordinators of operations. The software element and the physical entity, coupled by a suitable communications network (see Figure 13.1) represent the different manufacturing holons for this process. Each of these holons - once created - is assumed capable of a degree of local reasoning and decision making and an ability to communicate in an interactive manner with other holons. We will discuss the way in which these capabilities support different production planning and control issues in the next section.

For more details on the descriptions and architectures of individual holons and their interconnection systems, the reader is referred to [13.12, 13.17, 13.67, 13.71]. For example, the so called Product - Resource - Order - Staff Architecture (PROSA) proposed in [13.68] has been widely adopted and more recently an architecture based only on the nesting of a Product - Resource model - the so called Holonic Component Based Architecture (HCBA) - has been developed [13.15]. 


\subsubsection{Review of Developments in Holonic Control Algorithms}

This section is intended to briefly summarise the current work relating to the algorithms deployed between holons in order to generate production control solutions. For more details the reader is referred to [13.47], in which a comprehensive review of holonic production planning and control is carried out.

We shall describe how the current developments in holonic control research apply to each of the control activities listed in Fig 13.6, (i.e. planning and scheduling, shop floor control and execution and machine \& device control).

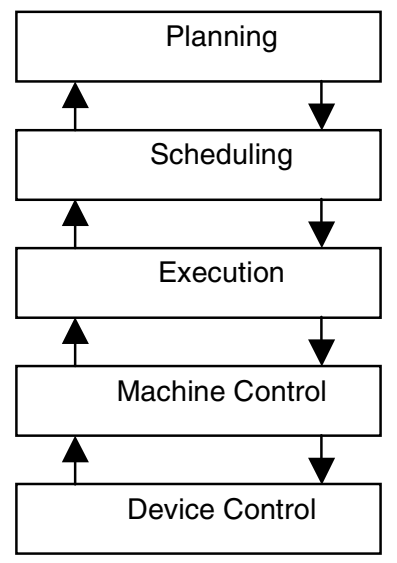

Fig. 13.6. Typical manufacturing control hierarchy

The solutions for holonic control we will be discussing will mainly address only one of the control issues in Fig 13.6 at a time, and can be seen as providing partial holonic solutions of the form in Fig 13.7. That is each, separate control function in the decision making hierarchy in Figure 13.6 can be addressed by a partial holonic solution.

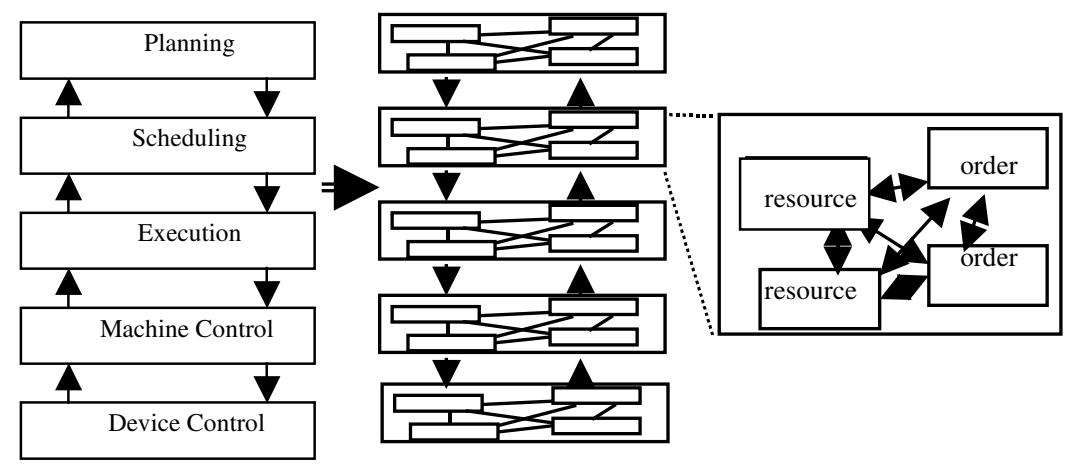

Fig. 13.7. Partial holonic control solution 
Planning and Scheduling. We restrict the following discussions on production planning to a) the decomposition of an order into a sequence of production operations and b) the nominal allocation of operations to resource types (but not to specific resources or times). Approaches to holonic planning typically involve a number of the following steps:

1. Each product holon performs a decomposition of the supplied product specification into constituent parts or sub-assemblies.

2. For each product, the manufacturing operations needed are identified (by the product holon).

3. The types of resources needed to provide operations are selected via interaction approach between product and resource holons.

4. An interactive process involving resource holons and product holons is used to determine a suitable set of operations.

5. A full make sequence (assembly plan) is finalised and this normally resides in the product holon.

We note that this assumes - a priori - that the products required to fulfil an order have already been identified and also that either the product or the resource is coordinating the planning process. The benefits of a holonic approach compared with more conventional approaches are principally due to the distributed and interactive nature of the planning process, enabling new products and/or production resources to be introduced without major system alterations. The close connection between the individual holons and the physical resources they represent also enables planning to maintain a close alignment with the (dynamically changing) capabilities available on the shop floor. Holonic planning approaches have been reported in $[13.4,13.20,13.21$, $13.28,13.29,13.30,13.31,13.32,13.55]$.

Similarly, we assume that scheduling simply involves (a) the allocation of production operations to specific resources and (b) the specification of the timing (start, duration, completion) for those operations. The key characteristics which typify a holonic scheduling approach are [13.47]:

1. A local decision-making and computational capability associated with each holon.

2. A cooperative interaction strategy which governs the way in which holons exchange information and determine mutually acceptable solutions.

3. An interchange mechanism or protocol which manages the exchange of the message types needed to execute the cooperative strategy.

4. A means of ensuring that the global concerns of the factory are addressed.

5. A degree of central coordination (not present in all solutions).

Work on holonic scheduling to date $[13.1,13.11,13.28,13.29,13.31,13.32,13.43$, $13.50,13.53,13.60]$ has predominantly experimented with different algorithms and simulated testing although issues such as the desire for an emergent schedule vs. a fixed schedule structure, and the relationship between scheduling and execution has been examined also. 
Execution and Shop Floor Control. Execution or shop floor control involves the initiation, control, monitoring and termination of tasks and involves actual times and actual production settings. Within a holonic manufacturing system, execution is predominantly concerned with (a) ensuring that the holon is capable of establishing and maintaining autonomous operations and (b) that it undertakes tasks compatible with production requirements even in the face of disruptions. Execution has been addressed in the holonic literature by [13.27, 13.31, 13.32, 13.66], where the autonomous behaviour of the (resource) holons in each case is managed by an internal model of the operations. Such a model is an essential requirement for the holon's selfmanagement. The novel elements of a holonic approach to execution are that a) execution proceeds via a negotiated set of steps rather than a predetermined sequence and that b) the resources (machines) executing the manufacturing operation are also responsible for the decisions made about the timing and nature of the execution. A further important issue is the relationship between execution and scheduling which has been discussed in [13.54, 13.66, 13.69].

Machine and Device Control. In a holonic system, machine control - which involves the initiation, coordination and monitoring of the different machine functions or devices required to support the execution of production tasks by an individual machine - has been largely treated as a conventional control problem coupled to a higher level holonic operation. (See for example $[13.3,13.54,13.61,13.62,13.71]$. The focus in these cases has been on achieving effective interfaces. Only in [13.51] is the possibility of a machine itself running on holonic principles truly considered where the interactions of the individual devices which constitute a machine are determined cooperatively. There has been even less work in the device area - that is, the actuation, sensing and feedback control of the physical operations which support a machine - but most of the above comments also apply.

Although developments in both holonic machine control and holonic device control have been limited to date, opportunities for greater flexibility and disturbance handling present themselves in the way in which trajectories and control actions could be negotiated to suit the current operational environment rather than following predetermined paths. One would expect such a system to be more adaptable to changing conditions arising, for example, from wear, damaged parts, faulty components or faulty sensors.

\subsubsection{Summary of Developments}

The concepts that were described as underpinning the holonic approach in Section 13.2 were the holonic structure and properties of autonomy, cooperation, selforganisation and reconfigurability. Examining the results of this section's review, we see that (a) numerous architectures for holonic manufacturing systems have been proposed, (b) cooperative mechanisms have been explored to a degree within the different production control levels, and (c) requirements for autonomy have been established, particularly with regard to the lower-level control functions in Fig 13.6. However, apart from organisational aspects associated in holonic planning there has been little or no attempt to explicitly address the requirements for selforganisation which under- 
pin the flexible response of a holonic system. (Issues of reconfigurability are primarily associated with architectural rather than algorithmic considerations and therefore can not be assessed directly here.)

In addition, there are more practical issues requiring attention. In the next section we shall summarise a number of outstanding issues that need to be addressed before widespread applications of holonic control systems can be considered.

\subsection{Open Issues}

In this section we address a number of significant open issues that must be addressed before holonic control solutions can be expected to play any significant part in next generation manufacturing systems. We examine issues in both the design and implementation of holonic control systems and then explore possible application areas beyond discrete manufacturing.

\subsubsection{Open Issues in Holonic Control System Design}

There are a number of key design issues that must be addressed before holonic control solutions can be expected to play any significant part in next generation manufacturing production systems. These points reflect the fact that to date many of the developments described in Section 13.2 have been of an exploratory nature, and there is a definite need now to move to a more rigorous, scientific assessment of the designs that have been proposed.

- Availability of proven design methodologies: Only when definitive methodologies have been produced which provide clear, unambiguous guidelines can it be expected that a level of consistency and reliability will emerge in holonic control system design. To date, there have been no two applications built following the same design methodology and hence it is very difficult to evaluate the potential reusability of any method specified. The lack of effective methodologies also means that researchers in the area have no common base for their own developments which is clearly inefficient.

- Analysis of the performance of holonic manufacturing systems: A limitation in the research to date has been the lack of assessment of the relative performance of the control mechanisms that the holonic manufacturing systems support. In particular, holonic manufacturing systems are frequently cited as performing well in the face of disturbances, but there has been little reported evidence of them being shown to do so. Any serious industrial commitment to holonic manufacturing systems in the future will require a demonstrated ability to improve performance beyond that of conventional systems. To be fully effective, holonic manufacturing requires a complete reorganisation of production operations, which is a costly undertaking. Therefore, it is very important to show and quantify the benefits as is done for example in [13.14]. 


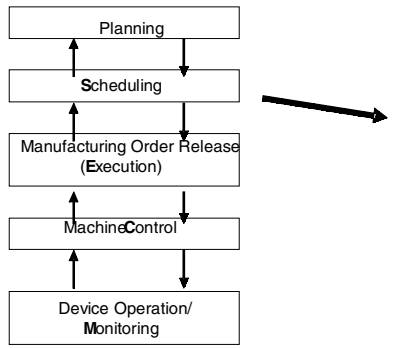

(a) Conventional centralised approach

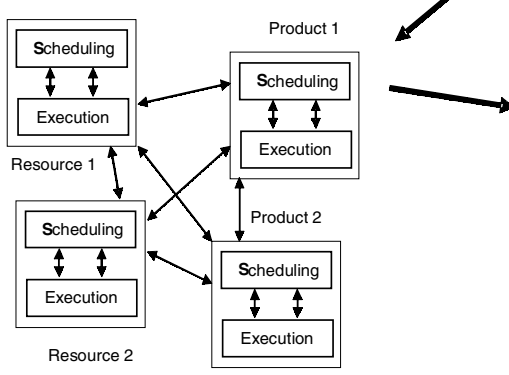

(c) Combined holonic control solutions

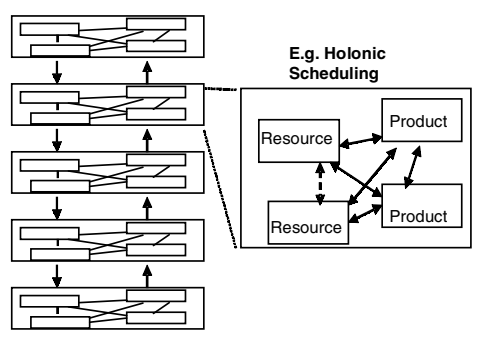

(b) Individual holonic control solutions

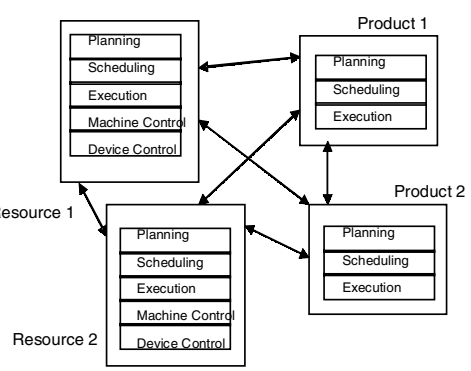

(d) Full holonic control solutions

Fig. 13.8. Migration to holonic control algorithms

- Migration to full holonic manufacturing control algorithms: The review in Section 13.3 reflects a research activity that has to date aligned itself with the conventional control systems hierarchy in Fig 13.7. That is, distributed, cooperative solutions have been sought for each of the individual problems on this hierarchy. Few authors, however, have truly attempted to question the relatively static commandresponse connections between these layers. These current developments are illustrated in 13.8(b). It is the authors' opinion that a new, more holistic approach is required for the control of manufacturing operations, which seeks to achieve cooperative interaction across these layers as well as between elements within them. For example, a separate planning and scheduling phase is in fact restrictive, because planning can commit an order to a particular make sequence when in fact more than one may be possible and each option may be more or less desirable depending on the current plant state. Hence combining planning and scheduling may be highly attractive, at least if planning options are not deleted until scheduling is considered. A distributed, interactive approach to combined planning and scheduling, to combined scheduling and execution or even to combined execution and control should present a relatively straightforward migration from the current state of development. (See Fig. 13.8 (c)). From these combined solution approaches, the next migration step is to consider systems which support comprehensive manufacturing holons that can seamlessly integrate all of the five control functions into their operations (Fig. 13.8 (d)). We emphasise that at this stage Fig. 13.8(d) is very 
much a target, and it has not yet been demonstrated that distributed planning and scheduling functions can coexist with execution and control functions within a single logical unit.

\subsubsection{Open Issues in Holonic Control Systems Implementation}

Assuming that the a well defined holonic control design process is available with performance guarantees established, it is also important to ensure an effective environment for implementation. The following items identify some of the key issues to be considered in implementing and maintaining an effective holonic control environment.

- Establishing suitable implementation architectures compatible with existing and future commercial computing systems: There has been little work done on determining the compatibility of the holonic control with the current or the next generation of industrial control and computing systems. Holonic systems will require a high level of reasoning and computational capability at the shop floor level, coupled with more flexible communication and more dynamic interfaces to human operators and users. Determining how to construct and implement system architectures capable of fully supporting holonic operations while still operating with existing legacy systems will also be a major issue as the capabilities of holonic systems reach industrial strength. In the shorter term, suitable migration approaches for the implementation of intermediate holonic control capabilities are required (see, for example [13.16, 13.27]), and effort is required to ensure systems vendors can access and adopt these approaches.

- Appropriate environments for implementing holonic control: For a successful, effective implementation which achieves the target behaviour outlined in Section 13.2, the holonic control system is ideally be complemented by several other features in a production environment:

- flexible resources (e.g. machines, storage and transportation systems) providing redundancies of function, operation and/or routing

- flexible networking environments for both resources and raw materials / products enabling accurate monitoring of highly varied operations (e.g. the latter is the aim of the Auto ID project which Unilever sponsors through its Digital Futures Laboratory)

- flexible and empowered manpower base: HMS enhances the role of the skilled operator in assisting with disturbance handling

- flexible business information systems enabling inter-site interactions between devices, resources and orders to be as flexible as those provided by holonic control systems within an operational site

Under these conditions the flexible decision making policies afforded by holonic control system create the greatest value. Conversely, the implementation of a holonic control system on a single product, serial, production line with few variations or alternative operating scenarios and little operator intervention possible would be largely pointless.

- Establishing suitable standards for holonic control systems: Before any industrial confidence in holonic manufacturing systems can be established, a comprehensive 
set of standards is required for the open specification of communications, data formats, systems architectures, algorithms and interfacing of holonic systems. There has to date been no comprehensive study of the requirements for standards in this area.

\subsubsection{Other Applications for Holonic Control Systems}

Holonic manufacturing has almost exclusively focussed on production applications within the discrete manufacturing domain. We note that there is considerable potential for applying the same approaches within other application domains:

- Process control systems based on holonic principles: In [13.18] it is noted that process industries today form a major part of the GDP within the economy of every nation. In general, process industries cover a very large and diverse sector of industries including petrochemicals, polymers, bulk and specialities chemicals and related utilities sectors. Historically, the processes have evolved from small scale, simple units, which were often operated in batch or semi-continuous mode. Energy and primary raw materials were relatively plentiful. Large and attractive profit margins were the basis on which these industries have grown at such a rapid rate. Over the last two decades, however, this sector of manufacturing has also experienced an important change, owing primarily to increasing energy costs and increasingly strict environmental regulations. Growing competitive markets demanding "mass customisation" of products and rapid technological innovations are replacing the old style of mass production and copycat- type R\&D structures. There is also now a growing emphasis on improving efficiency and increasing the profitability of existing plants rather than creating plant expansions. In a similar manner to that described in Section 13.2, a set of rationales has been developed for applying holonic manufacturing principles as a technological solution to the growing business concerns in the chemical process industries. The anticipated benefits from holonic approach stem from the use of a distributed control systems architecture that supports flexible operations of units that can dynamically integrate and collaborate with others as and when the production conditions change.

- Holonic manufacturing applications in the supply chain: The restrictions to date of holonic control applications to production applications alone is rather artificial and a consequence of the origins of this movement from within the production control community. Holonic control concepts are applicable in any operation where there is benefit to be extracted from an increased level of autonomous, distributed decision making. As noted above, this is closely aligned to the flexibility and reconfigurability of the physical resources that will execute the actions resulting from these decisions. We note that a number of applications in supply chain logistics clearly fit this description. In fact, noting that holonic control concepts are best suited to environments in which a high degree customisation and of response to disturbances is required, it may in fact be more appropriate to prioritise holonic control applications for those activities in the supply chain closest to the endcustomer. This is depicted in Figure 13.9. Stated simply, the closer the operation is to the end customer, the more the need for rapid customer response and the greater the need to introduce late customisation in order to address a specific customer need. In the case of detergent powder manufacture, for example, while the basic 
chemicals are produced in bulk and even the detergent manufacturing is quite generic, the packaging of the product and its subsequent distribution processes are very highly geared towards changing customer needs. Hence the operations need to be able to respond quickly to a new order, a packaging variation or an increased volume requirement.

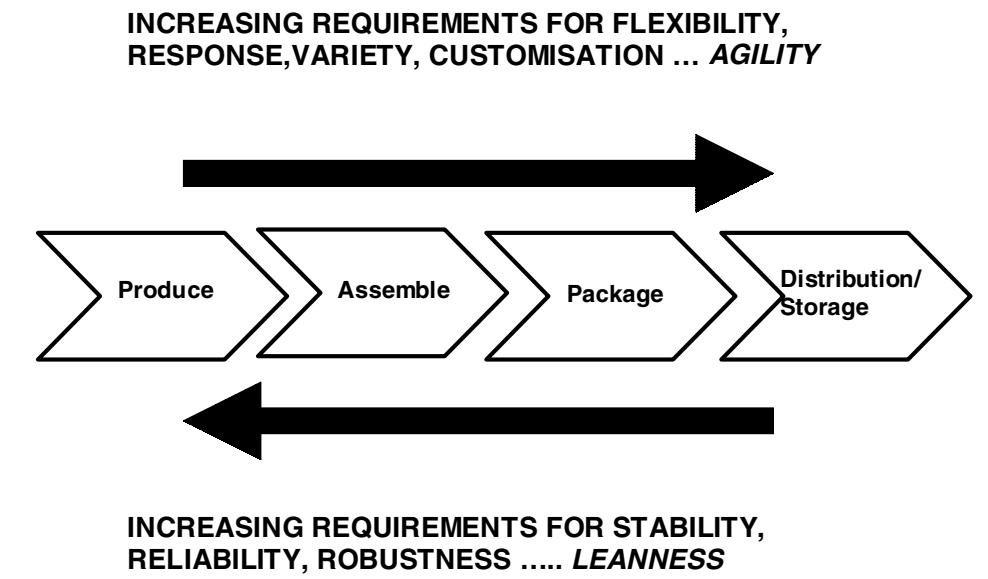

Fig. 13.9. Requirements variation along the supply chain

We conclude this section by noting that even restricting applications of holonic control system to the manufacturing supply chain may also be unnecessarily constraining. If the principles and their implementation can be well proven and demonstrated to be repeatable, then countless other opportunities present themselves.

\subsection{Acknowledgements}

The authors are grateful for the support and help of Hartwig Baumgärtel and Sven Broekner at Daimler Chrysler; Jeremy Matson, Jin Lung Chirn, Martin Kollingbaum, Alan Thorne, C Y Wong and Nirav Chokshi at the University of Cambridge; Dennis Jarvis, Jacquie Jarvis, Andrew Lucas and Martyn Fletcher at Agent Oriented Software; Roy Johnson at OMRON; and Andrew McDonald at Unilever.

\section{References}

[13.1] Agre, J., Elsley, G., McFarlane, D., Cheng, J., and Gunn, B., 1994, Holonic Control Of Cooling Control System, Proceedings Of Rensslaers Manufacturing Conference (New York).

[13.2] Baker, A., 1998, A Survey Of Factory Control Algorithms Which Can Be Implemented In A Multi-Agent Heterarchy: Dispatching, Scheduling, And Pull. Journal of Manufacturing Systems, 17,(4),297-320.

[13.3] Bengoa, A., 1996, An Approach To Holonic Components In Control Of Machine Tools. Annals of CIRP, 45,(1). 
[13.4] Biswas, G., Sugato, B., And Saad, A., 1995, Holonic Planning And Scheduling For Assembly Tasks, Internal Report CIS-95-01, Centre For Intelligent Systems, Vanderbilt University, Nashville, TN.

[13.5] Bongaerts, L., Monostori, L., McFarlane, D., And Kadar, B., 1998a, Hierarchy in Distributed Shop-Floor Control, Proceedings of IMS'98 - ESPRIT Workshop in Intelligent Manufacturing Systems (Lausanne, Switzerland).

[13.6] Bongaerts, L., Monostori, L., McFarlane, D., And Kadar, B., 2000, Hierarchy in Distributed Shop-Floor Control. Computers in Industry, v43, n2, pp123-137.

[13.7] Bongaerts, L., Van Brussel, H., And Valckenaers, P., 1998, Schedule Execution Using Perturbation Analysis, Proceedings of IEEE International Conference on Robotics And Automation (Leuven, Belgium), 2747-2752.

[13.8] Bongaerts, L. B., Van Brussel H. Valckenaers, P. Peeters, P, 1997, Reactive Scheduling in Holonic Manufacturing Systems: Architecture, Dynamic Model And Cooperation Strategy, Proceedings of Advanced Summer Institute of The Network of Excellence on Intelligent Control And Integrated Manufacturing Systems (Budapest).

[13.9] Bongaerts, L. V., P. Brussel, Van, H. Peeters, P., 1997, Schedule Execution in Holonic Manufacturing Systems, Proceedings of 29th CIRP International Seminar on Manufacturing Systems (Osaka).

[13.10] Brennan, R., Balasubmramanian, S., And Norrie, D., 1997, Dynamic Control Architecture For Advanced Manufacturing Systems, Proceedings of International Conference on Intelligent Systems For Advanced Manufacturing (Pittsburgh, PA).

[13.11] Brown, J., And Mccarragher, B., 1998, Maintenance Resource Allocation Using Decentralised Co-Operative Control, Internal Report, Australian National University, (Canberra, Australia).

[13.12] Bussmann, S., 1998, An Agent-Oriented Architecture For Holonic Manufacturing Control, First Open Workshop, Proceedings of IMS98 - ESPRIT Workshop in Intelligent Manufacturing Systems (Lausanne, Switzerland).

[13.13] Bussmann, S., And McFarlane, D., 1999, Rationales For Holonic Control Systems, Proceedings of IMS99 (Leuven, Belgium).

[13.14] Bussmann, S., Sieverding, J, 2001, Holonic Control of an Engine Assembly Plant An Industrial Evaluation, Proceedings of IEEE SMC Conference, Tucson.

[13.15] Chirn, J.-L., And McFarlane, D. C., 1999, A Holonic Component-Based Architecture For Manufacturing Control Systems, Proceedings of MAS99 (Vienna).

[13.16] Chirn, J.-L., And McFarlane, D. C., 2000, Application of A Holonic ComponentBased Architecture For The Control of A Robot Assembly Cell, in Proceedings of IEEE Robotics And Automation, 2000 (San Francisco).

[13.17] Christensen, J., 1994, Holonic Manufacturing Systems - Initial Architecture And Standards Directions, First European Conference on Holonic Manufacturing Systems, (Hannover, Germany).

[13.18] Chokshi, N, McFarlane, D, 2001, Rationales for Holonic Manufacturing Systems in the Chemical Process Industries, Proceedings of HOLOMAS 2001, France.

[13.19] Czerwinski, C., And Luh, P., 1994, Scheduling Products With Bills of Materials Using An Improved Lagrangian Relaxation Technique. IEEE Transactions on Robotics And Automation, 10, (2).

[13.20] Deen, S. M., 1993, Co-Operation Issues in Holonic Manufacturing Systems. H. Yoshikawa, Goossenaerts, J, Ed., Information Infrastructure Systems For Manufacturing, (Elsevier Science B V), 401-412.

[13.21] Deen, S. M., 1994, A Co-Operation Framework For Holonic Interactions in Manufacturing. CKBS94: Proceedings of The Second International Working Conference on Cooperating Knowledge Based Systems, 103-124.

[13.22] Dilts, D. M., Boyd, N. P., And Whorms, H. H., 1991, The Evolution of Control Architectures For Automated Manufacturing Systems. Journal of Manufacturing Systems, 10, (1), 79-93. 
[13.23] Duffie, N., Chitturi, R., Mou, J., 1988, Fault Tolerant Heterarchical Control of Heterogeneous Manufacturing Entities. Journal of Manufacturing Systems, 7, (4).

[13.24] Duffie, N., And Piper, R., 1987, Non Hierarchical Control of A Flexible Manufacturing Cell. Robotics And Computer Integrated Manufacturing, 3,(2).

[13.25] Duffie, N., And Prabdu, V., 1994, Real Time Distributed Scheduling of Heterarchical Manufacturing Systems. Journal of Manufacturing Systems, 13, (2).

[13.26] Durna, M., Erkmen, I., Erkmen, A., 1998, Holonic Grasping, IEEE International Conference on Intelligent Robots And Systems (Victoria, Canada), 140-145.

[13.27] Gayed, N., Jarvis, D., And Jarvis, J., 1998, A Strategy For The Migration of Existing Manufacturing Systems To Holonic Systems, IEEE International Conference on Systems, Man And Cybernetics (San Diego), 319-324.

[13.28] Gou, L., Hasegawa, T., Luh, P., Tamura, S., And Oblak, J., 1994, Holonic Planning And Scheduling For A Robotic Assembly Testbed, Proceedings of The 4th Rensselaer International Conference on Computer Integrated Manufacturing and Automation Technology. (Rensselaer, NY).

[13.29] Gou, L., Luh, P., And Kyoya, Y., 1998, Holonic Manufacturing Scheduling: Architecture, Cooperation, Mechamism, And Implementation. Computers in Industry, 37, (3), 213-231.

[13.30] Hasegawa, T., Gou, L., Tamura, S., Luh, P., And Oblak, J., 1994, Holonic Planning And Scheduling Architecture For Manufacturing, Proceedings of The International Working Conference on Cooperative Knowledge Based Systems (Keele, UK) ,141157.

[13.31] Heikkila, T., Jarviluoma, M., And Hasemann, J., 1995, Holonic Control of a Manufacturing Robot Cell, Internal Report, VTT Automation (Oulu, Finland).

[13.32] Heikkila, T., Jarviluoma, M., And Juntunen, T., 1997, Holonic Control For Manufacturing Systems: Design of A Manufacturing Robot Cell. Integrated Computer Aided Engineering, 4,,202-218.

[13.33] Hoitomt, D., Luh, P., And Pattipati, K., 1993, A Practical Approach To Job Shop Scheduling Problems. IEEE Transactions on Robotics And Automation, 9,(1).

[13.34] Honma, N., Abe, K., Sato, M., And Takeda, H., 1998, Adaptive Evolution of Holon Networks By An Autonomous Decentralized Method. Applied Mathematics And Computation, 91, (1), 43-91.

[13.35] Jennings, N. R., 1996, Coordination Techniques For Distributed Artificial Intelligence. G. M. P. Ohare And N. R. Jennings, Eds., Foundations of Distributed Artificial Intelligence, (Wiley), 429-447.

[13.36] Kawage, M. et al, 1994, Holonic Control of An Assembly Robot, Annual Conference of Robotics Society of Japan (Japan).

[13.37] Koestler, A., 1967, The Ghost in The Machine (Hutchinson).

[13.38] Kruth, J. P. D., J. Prianggada,I.T. Ginderachter, T Van. Wyns, J., 1996, An NC Holon Architecture, Proceedings of CNMU96 Machine Tool National Conference (Bucharest).

[13.39] Kusumi, N., Hirasawa, K., And Obayashi, M., 1998, Holonic Control System Based on A Universal Learning Network. Electrical Engineering in Japan, 124,(4),64-72.

[13.40] Langer, G.: A Methodology And Architecture For Holonic Multi-Cell Control Systems, PhD Thesis, Technical University of Denmark, (Lyngby, Denmark, 1999).

[13.41] Lin, G., And Solberg, J., 1992, Integrated Shop Floor Control Using Autonomous Agents. IIE Transactions, 24,(3),169-206.

[13.42] Lin, G., And Solberg, J., 1994, Autonomous Control For Open Manufacturing Systems. S. Joshi, Smith, J, Ed., Computer Control of Flexible Manufacturing Systems, (Chapman-Hall), London, 169-206.

[13.43] Marcus, A., Kis Vancza, T., And Monostori, L., 1996, A Market Approach To Holonic Manufacturing. Annals of CIRP, 45,(1),433-436.

[13.44] Marik, V, Pechoucek, M, (eds.), 2000, Proceedings of Holomas 2000 - First International Workshop on Industrial Applications of Holonic and Multi-Agent Systems, London. 
[13.45] Matthews, J., 1995, Organisational Foundations of Intelligent Manufacturing Systems - The Holonic Viewpoint. Computer Integrated Manufacturing Systems, $8,(4), 237-243$.

[13.46] McFarlane, D., Marett, B., Elsley, G., And Jarvis, D., 1995, Application of Holonic Methodologies To Problem Diagnosis in A Steel Rod Mill, Proceedings of IEEE Conference on Systems, Man And Cybernetics (Vancouver).

[13.47] McFarlane, D., and Bussmann, S, 2000, State of the Art of Holonic Systems in Production Planning and Control, International Journal of Production Planning and Control, v11, n6, pp522-536.

[13.48] McFarlane, D. C., 1995, Holonic Manufacturing Systems in Continuous Processing: Concepts And Control Requirements, Proceedings of ASI 95 (Portugal).

[13.49] MESA International, 1995, "Controls Definition \& MES To Controls Data Flow Possibilities", White Paper, www.mesa.org.

[13.50] Ng, A., Yeung, R., And Cheung, E., 1996, HSCS - The Design of A Holonic Shopfloor Control System, Proceedings of IEEE Conference on Emerging Technologies And Factory Automation, 179-185.

[13.51] Overmars, A., And Toncich, D., 1996, Hybrid FMS Control Architectures Based on Holonic Principles. International Journal of Flexible Manufacturing Systems, 8,,263278.

[13.52] Prosser, P., And Buchanan, I., 1994, Intelligent Scheduling: Past, Present And Future. Intelligent Systems Engineering (Summer Issue).

[13.53] Ramos, C., 1996, A Holonic Approach For Task Scheduling in Manufacturing Systems, Proceedings of IEEE Conference on Robotics And Automation (Minneapolis ), 2511-2516.

[13.54] Rannanjarvi, L, And Heikkila, T, 1998, Software Development For Holonic Manufacturing Systems. Computers in Industry, 37,(3),233-253.

[13.55] Saad, A., Kawamura, K., And Biswas, G., 1997, Performance Evaluation of Contract Net Based Hierarchical Scheduling For Flexible Manufacturing Systems, Internal Report, Center For Intelligent Systems, Vanderbilt University, (Nashville).

[13.56] Smith, R. G., 1980, The Contract Net Protocol: High-Level Communication And Control in A Distributed Problem Solver. IEEE Transactions on Computers, C29,(12).

[13.57] Sousa, P., Ramos,C, 1998, Dynamic Scheduling Holon For Manufacturing Orders. Journal of Intelligent Manufacturing, 9,(2),107-112.

[13.58] Suda, 1989, Future Factory System Formulated in Japan. Techno Japan, 22,(10),1525.

[13.59] Suda, 1990, Future Factory System Formulated in Japan (2). Techno Japan, 23,(3),51-61.

[13.60] Sugimura, N., Hiroi, M., Moriwaki, T., And Hozumi, K., 1996, A Study on Holonic Scheduling For Manufacturing System of Composite Parts, Japan/USA Symposium on Flexible Manufacturing, 1407-1410.

[13.61] Tanaya, P., Detand, J., And Kruth, J.-P., 1997, Holonic Machine Controller: A Study And Implementation of Holonic Behaviour To Current NC Controller. Computers in Industry, 33,325-333.

[13.62] Tanaya, P., Detand, J., Kruth, J.-P., And Valkenaers, P., 1998, Object-Oriented Execution Model For A Machine Controller Holon. European Journal of Control, 4,(4),345-361.

[13.63] Tharumarajah, A., And Wells, A., 1996, Behaviour-Based Approach To Scheduling in Distributed Manufacturing Systems. Integrated Computer-Aided Engineering (Special Issue on Intelligent Manufacturing Systems).

[13.64] Thompson, D., And Hughes, D., 1996, Holonic Approach To CIM Architecture And Systems Design, Proceedings of IEE Colloquium on Systems Approach To Manufacturing, England. 
[13.65] Valckenaers, P., Bonneville, F., Van Brussel, H., Wyns, J., 1994, Results of The Holonic Control System Benchmark At K U Leuven, Proceedings of Computer Integrated Manufacturing and Automation Technology (Troy, NY) ,128-133.

[13.66] Valckenaers, P., Van Brussel, H., Bongaerts, L., And Bonneville, F., 1995, Programming, Scheduling And Control of Flexible Assembly Systems. Computers in Industry, 26,,209-218.

[13.67] Van Brussel, H. V., P. Bongaerts, L. Wyns, J., 1995, Architectural And System Design Issues in Holonic Manufacturing Systems, Proceedings of 3 rd IFAC Workshop on Intelligent Manufacturing Systems (Bucharest).

[13.68] Van Brussel, H. W., J. Valckenaers, P Bongaerts, L. Peeters P., 1998, Reference Architecture For Holonic Manufacturing Systems. Computers in Industry, $37,(3), 255-274$.

[13.69] Wyns, J., Ginderachter, T., Valckenaers, P., Van Brussel, H., 1997, Integration of Resource Allocation And Process Control in Holonic Manufacturing Systems, 29th CIRP International Seminar on Manufacturing Systems (Osaka), p57-62.

[13.70] Wyns, J. B., Van. H. Valckenaers, P. Bongaerts, L., 1996, Workstation Architecture in Holonic Manufacturings Systems, 28th CIRP International Seminar in Manufacturing Systems (Johannesburg).

[13.71] Zhang, X., And Norrie, D., 1999a, Holonic Control At The Production And Controller Levels, Proceedings of IMS99 (Leuven, Belgium).

[13.72] Zhang, X., And Norrie, D. H., 1999b, Dynamic Reconfiguration of Holonic Lower Level Control, Proceedings of IPMM '99 (Honolulu).

[13.73] Zweben, M., And Fox, M., 1994, “Intelligent Scheduling.” (Morgan Kaufman). 